\title{
Hypoglossal Nerve Injury after Cervical Spine Surgery
}

\author{
Selahattin Ozyurek ${ }^{1}$, Aziz Atik ${ }^{2}$ \\ ${ }^{I}$ Department of Orthopaedics and Traumatology, Aksaz Military Hospital, Marmaris, Mugla, Turkey \\ ${ }^{2}$ Department of Orthopaedics and Traumatology, Balikesir University Hospital, Balikesir, Turkey
}

Dear Editor,

We have read with great interest the case report entitled "Hypoglossal nerve palsy as a complication of an anterior approach for cervical spine surgery" in the issue of Asian Spine Journal 2015;9(2):295-298, http://dx.doi. org/10.4184/asj.2015.9.2.295 [1]. We would like to commend the authors for their report on a complex and challenging case.

Hypoglossal nerve injury often follows soft tissue surgery of the neck but is extremely rare following surgery of the upper cervical spine [1,2]. In this article, the authors cited only one report of hypoglossal nerve palsy after anterior cervical spine surgery through the SmithRobinson approach $[1,2]$. Nevertheless, we would like to bring to our readers attention an additional case report on hypoglossal nerve injury following anterior surgery to the upper cervical spine. Saunders et al. [3] reported one incidence of hypoglossal palsy as a long-term sequela in a review of 40 cases of central corpectomy for cervical spondylotic myelopathy.

However, we have some concerns regarding the case report and wish to share them with our readers. Hypoglossal nerve injury may be missed unless the deviation of the tongue is noticed carefully. In the cases reported by
Saunders et al. [3] and Sengupta et al. [2], the paresis did not recover. Sengupta et al. concluded that together with a review of literature, the hypoglossal nerve should be carefully identified before ligating any large blood vessel in the anterior approach to the upper cervical spine. Spontaneous recovery of hypoglossal palsy may not always be expected.

We also agree with the authors that meticulous tissue dissection and hemostasis should be performed intraoperatively to prevent these adverse events. Relaxing the retractors during surgical procedure will minimize traction injury to neural structures. In addition, the patient should be warned about this complication.

We highly appreciate the authors' contribution to the increase in our knowledge of this difficult clinical problem.

\section{Conflict of Interest}

No potential conflict of interest relevant to this article was reported.

\section{References}

1. Yasuda T, Togawa D, Hasegawa T, et al. Hypoglossal

Received Apr 29, 2015; Accepted Apr 29, 2015

Corresponding author: Selahattin Ozyurek

Department of Orthopaedics and Traumatology, Aksaz Military Hospital, 48700 Marmaris, Turkey

Tel: +90-2524210161, Fax: +90-2524210415, E-mail: fsozyurek@yahoo.com 
nerve palsy as a complication of an anterior approach for cervical spine surgery. Asian Spine J 2015;9:2958.

2. Sengupta DK, Grevitt MP, Mehdian SM. Hypoglossal nerve injury as a complication of anterior surgery to the upper cervical spine. Eur Spine J 1999;8:78-80.

3. Saunders RL, Bernini PM, Shirreffs TG Jr, Reeves AG. Central corpectomy for cervical spondylotic myelopathy: a consecutive series with long-term followup evaluation. J Neurosurg 1991;74:163-70. 